\title{
Effectiveness and Safety of Etanercept in Iraqi Patients with Ankylosing Spondylitis
}

\author{
Author \\ Dr. Majid Hamid Hussein
}

Ministry of Health / Baghdad Health Department /Almadain General Hospital / Iraq

Email/ mustafasaleamuob@gmail.com

Mobile/009647725503941 


\section{Abstract}

Background: Ankylosiong spondylitis (AS) is a chronic inflammatory disease that present as inflammation of the vertebrae and joints for which there is currently no cure, the aim of treatment is mainly symptomatic, maintain the functions and manage the complication. Etanercept is a biopharmaceutical component that treats autoimmune disease by interfering with tumor necrosis factor alpha soluble receptor.

Objective: To assess the effectiveness and safety of Etanercept in Iraqi ankylosing spondylitis patients.

Patients and methods: This was a single group open labeled observational study including 75 Iraqi patients with modified New York criteria of ankylosing spondylitis were recruited, patients received etanercept. And followed for 3 consecutive visits; 1 month, 3 months and 6 months. Disease activity was assessed at each visit by Bath ankylosing spondylitis disease activity index (BASDAI) and Bath ankylosing spondylitis function index (BASF!) for patients .The patients whom refused to participate, stopped the treatment or withdraw from the study and those whom loss to follow up were excluded from the study.

Results: The mean age of patients was $35.2 \pm 10$ years, males represented $92 \%$ of the cases, and the Mean disease duration was $9.29 \pm 7.1$ years. A highly significant decrease in BASFl and BASDAI, as compared to baseline, bad been found. Multiple logistic regression analysis revealed no significant association between each of age of the patients, disease 


\section{ABSTRACT}

duration, HLA-B27, fa1nily history of Psoriasis/IBO, NSAIDs intake and duration of smoking with changes in BASDAI, BASFI and functional class.

Conclusion: Etanerceptis effective and relatively safe in treatment of ankylosing spondylitis patients. 


\section{Introduction}

\section{Ankylosing spondylitis}

\section{Definition:}

Ankylosiong spondylitis (AS)is a chronic and systemic rheumatological disease that present as inflammation of the vertebrae and joints, The resultant stiffening of the joints attributable to that fusion is called ankylosis and extent of the fusion can vary from fusion of pelvic bone only, to fusion of the entire spine.(1)

Ankylosiong spondylitis affects young adult with peak age of onset between 20 and 30 years. (2)

\section{Epidemiology:}

Ankylosiong spondylitis is the most common of the classic spondyloarthropathies, prevalence varies with the prevalence of the HLAB27 gene. AS is more common in whites than in non whites, It occurs in 0.1 - $1 \%$ of the general population. (3.4.5)

Approtimately 1-2\% of all people who are positive for HLA-B27 develop A.S, this increase to $15-20 \%$ if they have a first - degree relative with HLA- B27.(6.7)

Three males are diagnosed Ankylosiong spondylitis for every one female, the overall prevalence is $0.25 \%$. (8)

Definite AS was observed in $0.07 \%$ of the Iraqi population. (9) 


\section{Etiology:}

The etiology of AS is unknown, but a combination of genetic and environmental factors works $1 \mathrm{n}$ concert to produce clinical disease. (7)

The strong association of AS with HLA-B27 is a direct evidence of the importance of genetic predisposition, the genotypic of HLA-B27, HLA- $8 * 2705$ has the strongest association with the spondyloarthropathies HLA-B*2702, *2703, *2704, and 2707 are associated with AS.(10.11)

People who are homozygous for HLA-B27 are at a greater risk for AS than those who are heterozygous. (12)

Anlylosiong spondylitis is more common in persons with a family history of AS or another seronegative spondyloarthropathy.(13)

The shared amino acid sequence between the antigen - binding region of severed HLA-B27 genotypic subtypes, especially HLA-8*2705 and nitrogenase from klebsiella pneumonia support molecular mimicry as a possible mechanism for the induction of spondyloarthropathies in genetically susceptible hosts via an environmental stimulus including bacteria in the gastrointestinal tract.(14)

Smoking worsens the functional status of patient and led to the conclusion that older age and smoking are predictors of functional disability.(15)

\section{Sign and symptoms}

The typical patient is a young male. Symptoms of the disease first appear on average at age 23 , These first symptoms are typically chronic pain and stifflness in the middle part of the spine or sometimes the entire spine, often with pain referred to one or other buttock or the back of thigh from the sacroiliac joint.(16) 
Inflammatory back pain $i 11$ the most common symptom and the first manifestation in approximately $750 / 0$ of patients, insidious in onset persistent for more than 3 months worsened by rest and improved by Exercise night pain is a frequent symptoms • (17.18)

New criteria to define inflammatory back pain have been proposed; when 2 of the 4 criteria are present, they yield a sensitivity of $70.3 \%$ and specificity of $8 \mathrm{~J} .2 \%$.

These criteria include the following:

I. Morning stiffness that lasts more than 30 minutes.

2. Improvement of back pain with exercise but not rest.

3. Nocturnal back during second half of the night only.

4. Alternating buttock pain. (19)

\section{Extra-articular manifestations:}

The most common extra - articular manifestations are uveitis, bowel disease, lung, heart, skin, bone, and kidney involvement . (20)

Eye: uveitis also called iritis or iridocyclitis is the most common occurring in 20 - 30\% of patients, acute in presentation and unilateral, symptoms include a painful red eye with photophobia, increased lacrimation and blurred vision, usually anterior, but rarely include posterior element . (21.22)

Pulmonary Involvement; Restrictive lung disease may occur in patients in late stages, with costovertebral and costosternal involvement limiting chest expansion and pulmonary fibrosis of the upper lobes.(23)

Cardiovascular involvement; This occur in < I0\% of patients withsevere long standing disease. Aortitis, aortic regurgitation, fibrosis of the

conduction system results in various degree of atrioventriculer block including complete heart block.(23) 
Neurologic lesions: Neurologic deficits are associated cord or root lesions following spinal fracture (23)

Renal: secondary amyloidosis.(23)

Skin involvement: cutaneous manifestations, psoriasis has been observed in up to20\%ofthe patient as a secondary disorder in AS (24)

Bone involvement: Bone loss may be present early in the course of the disease and predominates at the spine, late in the disease vertebral fractures, large proportion of AS patients are either osteopenic or Osteoporotic (24)

\section{Diagnosis}

There is no direct test to diagnose AS. A clinical examination, MRI and x-ray studies of the spine., which show characteristic spinal changes and sacroilitis, and a simple genetic marker blood test are the major diagnostic tool.(25)

The diagnosis of AS must rest on the combination of clinical features, radiological findings and Jaboratory results.(26)

The most widely used classification criteria for AS are the modified New York criteria.(26) (appeodix 1)

The Bath Ankylosing spoodylitis disease activity index (BASDAI), developed in bath (United kingdome), is an index designed to detect the inflammatory burden of active disease, The BASDAI can help to establish a diagnosis of AS, it can be easily calculated and accurately assesses a patient's need for additional therapy, a patient with a score of four out of a possible 10 points while on adequate NSAID therapy is usually considered a good candidate for biologic therapy. (27)(appmdix ${ }^{2}$

The bath Ankylosing spondylitis functional index (BASFD is a functional index which can accurately assess a patient's functional 
impairment due to the dllealle $u$ well $u$ improvement following therapy. The BASFI ls not usually used as a diagnostic tool $\bullet$ but rather $u$ a tool to e11t11bl1Hh a patient's current baseline and subsequent response to therapy.(28X1pptnd• 3$)$

\section{Treatment:}

Ankylosing spondylitis is a chronic condition for which there is currently no cure. the aim of treatment is mainly symptomatic. maintain the functions and manage the complciation.(29)

Medication used to treat ankylosing spondylitis.

1. Nonsteroidal anti-inflammatory drugs (NSAJDs) first line drug treatment for patients with (AS) with pain and stiffness such as ibuprofen. diclofenac, indometbacin and cyclooxygenase-2 inhibitors.(30.31)

2. Analgesics

3. Opioid analgesics which are very effective in alleviating the type of chronic pain.(32)

4. Disease- modifying antirheumatic drugs $\left(\mathrm{DMARD}_{5}\right)$ :

5. There is no evidence for the efficacy of DMARDs. including sulfasalazine and methotrexate which are considered in patients with peripheral arthritis.(33)

\section{Glucocorticoids:}

Corticosteroid injection, intra - articular or local site injection are recommended for localized inflammation (ex : unilateral sacroilitis after exclusion of infection, Achilles enthesopathy), there is no evidence to support the use of intravenous, intramuscular, or oral corticosteroid in treating patient with (AS) . (34)

7. Tumor necrosis factor- alpha (I'NF) blockers (antagonists). 
Guidelines for the use of anti TNF- alpha agents in patients with AS in the United Kingdome (UK) were published in July 2004 by the British society for Rheumatology (BSR). These guidelines state that treatment with anti - TNF alpha agents may be appropriate for those patients who

(I) satisfy the modified New York criteria for the diagnosis of AS,

(2) have failed conventional treatment with two or more NSAIDs, and

(3) have active disease as defined by a bath Ankylosing spondylitis disease activity index (BASDAI) score. (35)

\section{Etanercept:}

Etanercept is a soluble fusion protein containing an FC fragment of human $\operatorname{lgGl}$ fused to two extra cellular domain of the P75 TNF receptor, Etanercept is given in dose of $50 \mathrm{mg}$ subcutaneously per week (altematively $25 \mathrm{mg}$ twice weekly).(36)

The prototypic fusion protein was first synthesized and shown to be highly active and usually stable as a modality for blockade of TNF in vivo in the early 1990 by Bruce A. Beutler, an academic researcher then at the university of Texas south western medical center at Dallas and his colleagues. Etanercept is a biopharmaceutical component that treats autoimmune disease by interfering with tumor necrosis factor alpha soluble receptor (TNF alpha soluble inflammatory cytokine) and acts asa TNF alpha inhibitor. TNF- alpha is the "master regulator" of the inflammatory (immune) response in many organ systems(37.38.39) 


\section{Side effect of etanercept: $(40)$}

1. Injection - site reaction,

2. Serious and some times fatal blood disorder (leucopenia, neutronpenia, thrombocytopenia) (pancytopenia).

3. Serious infection,.

4. Lymphoma and solid tissue cancer .

$S$. Reports of serious liver injury.

6. Reactivation of tuberculosis.

7. Reactivation of hepatitis $B$,

8. Drug- induced lupus,

9. Demyelinating central nervous system disorders.

1O.Psoriasis and psoriasis from skin lesions. 


\section{Aim of the Study:}

To assess the effectiveness and safety of Etanercept m Iraqi ankylosing spondylitis patients. 


\section{PATIENTS\& METHODS}

\section{Study design:}

This was a single group open labeled observational study.

Study setting and time:

The study was conducted at the Medical city during the period from the $t^{\text {st }}$ of January, to the $1^{\text {st }}$ of August, 2019

\section{Patients:}

A total of 75 Iraqi patients of both genders with proved diagnosed AS were recruited in this study.

The study was conducted on75 Iraqi patients with modified New York criteria of ankylosing spondylitis(appendix 1). Who attended to the Rheumatology Department in Baghdad Teaching Hospital.

Within the first month of follow up, 3 patients leave the treatment, and withdraw from the study, another 4 patients were switched to infliximab because they developed eye complications and only 68 patients completed three months of follow up, another 2 patients were also switched to infliximab the remaining 66 patients were completed the study.

Patients were received etanercept in a weekly dose of $50 \mathrm{mg}$ and followed up for 6 months in 3 consecutive visit, 1 month, 3 months and 6 months, during the study period.

\section{Inclusion criteria:}

Patients with proved diagnosed A.S. regardless the age or gender and agreed to participate in the study. 


\section{Methods}

\section{Data collection:}

The questionnaire sheet was collected the data in three parts:

1. Socio-demographic characteristics (Age, gender, occupation, smoking habits, disease duration, medication used, and family history of psoriasis or IBD). All were checked at the baseline visit.

The questionnaire sheet consists of two parts:-

\section{Investigations}

a. Laboratory investigation: including the Hemoglobin( $\mathrm{Hb})$,Erythrocyte Sedimentation Rate( ESR), White Blood Cells Count(WBC count),Aspartate Transaminase (AST),Alanine Tansaminase (ALT), blood urea and serum creatinin, these investigations were performed prior to initiation of medication and at each visit ( 1 month, 3 months, and after 6 months.

b. Radiological: X-ray of both sacroiliac joints was performed at the baseline visit and repeated after 6 months of follow up to those who completed the study, to assess the progression of the disease.

3. The assessment of disease activity by using Bath ankylosing spondylitis disease activity index (BASDAI) and functional status using Bath ankylosing spondylitis functional index (BASF!). 


\section{Statistica I Analvsis:}

Data of all patients were entered and analyzed by using the statistical package for social sciences (SPSS) version 18, software for windows, Data were presented as mean and standard deviation for continuous variables age, disease duration, BASDAI, BASFI and laboratory findings. The doses of medications used by the patients were presented as median and inter-quartile rang (IQR).

Categorical variables were presented as frequencies and percentage including gender, job, smoking, medication use, family history, HLAB27, functional class, X-ray stages.

Analysis of variances (ANOVA) test was used to compare the means of BASDAI, BASF! and laboratory findings and to assess the significance of changes in these variables at different time of follow up.

Chi-square test (\%2) was used for testing the significance of differences in the categorical variables (functional class, X-ray stages).Statistical significance was considered whenever the p-value was equal or less than 0.05 .

Results presented in tables and figures with explanatory paragraphs for each table and figure, using the Microsoft word software. 


\section{Results}

A total of 75 AS patients were recruited in this study. The baseline characteristics of them were shown in table 1. The Mean age of the patients was $35.2 \pm 10$ years and the age range was 18-59 years. Mean disease duration of studied AS patients was 9.29 \pm 7.1years with duration range 6 months-40 years. Sixty nine (92\%) patients were males and $6(8 \%)$ patients were females, table 1.

Among studied AS patients 36 (48\%) were employee, housewives were $6(8 \%)$, self-employers were $32(42.7 \%)$ and only one $(1.3 \%)$ retired patient More than one-third (34.7\%) of the patients were current smokers, $3(4 \%)$ patients were ex-smokers and $46(61.3 \%)$ patients were never smoked, table 1.

Positive HLA-B27 was present in $41(54.7 \%)^{\prime}$ studied AS patients, two patients (2.7\%) had family history of $\mathrm{mo}$ and 60 (80\%) patients were NSAIDs users, table 1. 


\section{Table 1. Baseline characteristics of study group ( $\mathrm{N}=750$}

\begin{tabular}{|c|c|c|}
\hline \multicolumn{2}{|l|}{ Variable } & value \\
\hline \multicolumn{2}{|c|}{ Age $\backslash$ mean $\pm \mathrm{SD}$ ( range) years } & $35.2 \pm 10(18-59)$ \\
\hline \multicolumn{2}{|c|}{ Disease duration $\backslash$ mean $\pm \mathrm{SD}$ ( range) yours } & $9.29 \pm 7.1(6$ month -40 years $)$ \\
\hline \multirow[b]{2}{*}{$\operatorname{Sex} \mathrm{n}(\%)$} & Male & $69(92)$ \\
\hline & Female & $6(8.0)$ \\
\hline \multirow{4}{*}{ Job o (\%) } & Employee & $36(48.0)$ \\
\hline & Housewife & $6(8.0)$ \\
\hline & Self-employer & $32(42.7)$ \\
\hline & Retired & $\mathrm{I}(1.3)$ \\
\hline \multirow{3}{*}{ Smoking n $(\%)$} & Current & $26(34.7)$ \\
\hline & Ex-smoker & $3(4.0)$ \\
\hline & Never & $46(61.3)$ \\
\hline \multicolumn{2}{|l|}{ Positive HLA -B27 n (\%) } & $41(54,7)$ \\
\hline \multicolumn{2}{|c|}{ Family History of IBD $\mathrm{n}(\%)$} & $2(2,7)$ \\
\hline NSAIDs users $\mathrm{n}(\%)$ & & $60(80.0)$ \\
\hline
\end{tabular}

. n (number)

- $\mathrm{SD}($ Standard deviation).

- HI.A (Human leukocyte Antigen).

- IBD (Inflammatory bowel disease).

- NSAIDs (Non Steroidal Anti lnfllminnlory drugs).

Methotrexate medication was used by 19 patients (25.3\%) with median dose $12.5 \mathrm{mg}$ (dose range 1 0-15 mg) and median duration of use was 5 months (duration range 3 - 48 months), table 2.

Sulfasalazine medication was used by 42 patients (56\%) with median dose $2 \mathrm{gn} 1$ (dose range 0.5 - $2 \mathrm{gm}$ ) and median duration of use was 6 months (duration range 2.25 - 24), table 2.

Chloroquine medication was used by one (35\%) patient with median dose 200 gmand median duration of use was 36 months, table 2. 
Prednisolone medication was taken by 18 patients (24\%) with median dose $10 \mathrm{mg}$ (dose range 5-1o $\mathrm{mg}$ ) and median duration of intake was 9 months (duration range 4-19.5). Injectable steroid medication was used in 2 patients $(2.7 \%)$ with irregular doses, table 2.

Infliximab medication was used by 6 patients( $8 \%)$ with median dose 7 (dose range 1-17 doses) and duration of use was 3 years. Adalimumb medication was taken by one $(1.35 \%)$ with median dose 4 , table 4 .

Table 2. Distribution use of Medication, doses and duration.

\begin{tabular}{|lcll|}
\hline Medication & $\begin{array}{c}\text { No. of users } \\
(\%)\end{array}$ & $\begin{array}{c}\text { Median Dose } \\
(\mathrm{IQR} \bullet)\end{array}$ & $\begin{array}{c}\text { Median duration } \\
(\mathrm{IQR}) \text { months }\end{array}$ \\
\hline MTX & $19(25.3)$ & $12.5(10-15) \mathrm{mg}$ & $5(3-48)$ \\
\hline SSZ & $42(56.0)$ & $2(0.5-2) \mathrm{gm}$ & $6(2.25-24)$ \\
\hline CQ & $1(1.35)$ & $200 \mathrm{mg}$ & 36 \\
\hline Steroid & & & \\
\hline PND & $18(24.0)$ & $10(5-10) \mathrm{mg}$ & \\
\hline Injectable & $2(2.7)$ & Irregular & $3(1-3)$ \\
\hline Biological agents & & & \\
\hline Infliximab & $6(8.0)$ & $7\{$ I - 17) doses \\
\hline Adalimumb & I $(1.35)$ & 4 doses & \\
\hline
\end{tabular}

- JQR (inter-quartile range)

- MTX (Methotrexate)

- SSZ(Sulfasalazine)

- CQ(Chloroquine)

- PND (Prednisolone)

The Mean baseline BASDAI of the patients was S.4 \pm 0.24 , after one month of weekly treatment with Etanercept medication, mean BASDAI of the patients was $4.3 \pm 0.20$, after three months the mean BASDAI changed to3.0 \pm 0.19 , reached to $2.2 \pm 0.12$ after six months. There was a significan de crease in BASDAI of the studied AS patients through the period of follow up of the patients after treatment with Etanercept medication $(\mathrm{p}<0.001)$ Mean difference in BASDAI vs. the baseline value 
was 1.lafter 
one month, 2.4 after 3 months and.3.2 after 6 months. The difference in BASDAJ was highly significant $(\mathrm{p}<0.001)$, indicatint the good effect of etanercept, table 3 and figure 1.

Mean baseline BASFI of the studied AS patients was $5.93 \pm 0.23$, decreased after one month to5.1 \pm 0.21 , after three to3.8 \pm 0.20 and after six months it was $2.9 \pm 0.10$, with a highly significant decrease in BASFI as compared to baseline $(\mathrm{p}<0.001)$.The mean difference in BASFI of the compared to baseline was 0.83 after one month 2.13 after 3 months and after 6 month the mean difference in BASFI was 3.03, and this difference was highly significant at all times of follow up, $(\mathrm{p}<0.001)$, table 3 and figure 2. All these findings indicating the effectiveness of etanercept in reduction of both disease activity and functional status.

Table 3.Comparison in mean BASDAI and mean BASFlat different follow up time.

\begin{tabular}{|lccccc|}
\hline \multicolumn{1}{|c}{ Variable } & $\begin{array}{c}\text { Baseline } \\
(\mathrm{n}=75)\end{array}$ & $\begin{array}{c}\text { I month } \\
(\mathrm{n}=72)\end{array}$ & $\begin{array}{c}3 \text { months } \\
(\mathrm{n}=68)\end{array}$ & $\begin{array}{c}6 \text { months } \\
(\mathrm{n}=66)\end{array}$ & P.value \\
\hline BASDAI & $\mathbf{5 . 4 \pm \mathbf { 0 . 2 4 }}$ & $\mathbf{4 . 3 : 1 : 0 . 2 0}$ & $3.0: 1: 0.19$ & $2.2 \pm 0.12$ & $<0.001$ \\
\hline $\begin{array}{l}\text { Mean difference } \\
\text { from Baseline }\end{array}$ & - & 1.1 & 2.4 & 3.2 & $<0.001$ \\
\hline BASFI & $5.93 \pm 0 ; 23$ & $5.1: 1: 0.21$ & $3.8: 1: 0.20$ & $2.9: 1: 0.10$ & $<0.001$ \\
\hline $\begin{array}{l}\text { Mean difference } \\
\text { from Baseline }\end{array}$ & - & 0.83 & 2.13 & 3.03 & $<0.001$ \\
\hline
\end{tabular}

- P.value (value of probabalty of error)

- BASDAI (Bath Anlcylosing Spondylitis Disease Activity Index)

- BASFI (Bath Anlcylosing Spondylitis Disease Functional Index) 


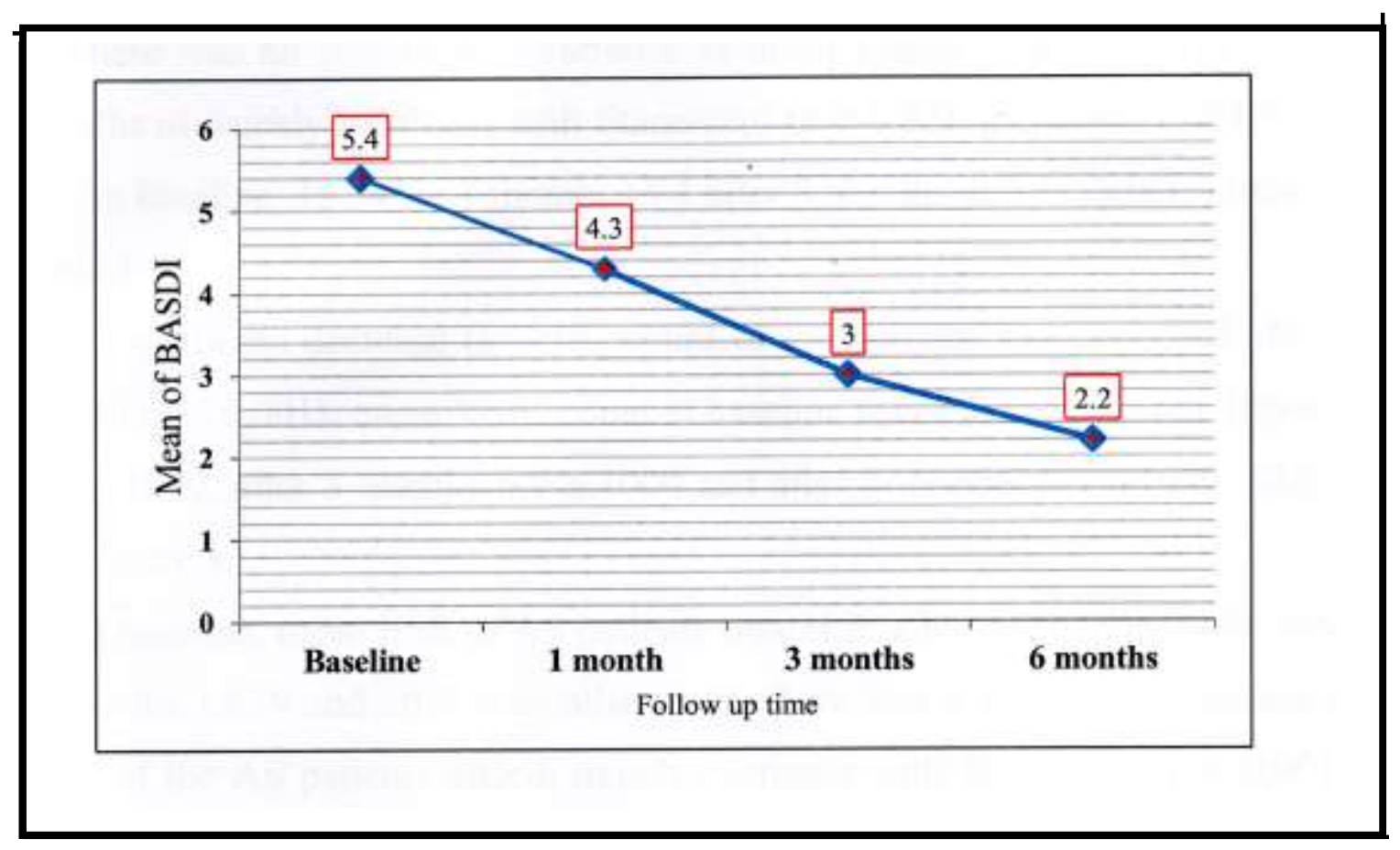

Figure I.Changes in BASDI throughout the time of follow up with treatment.

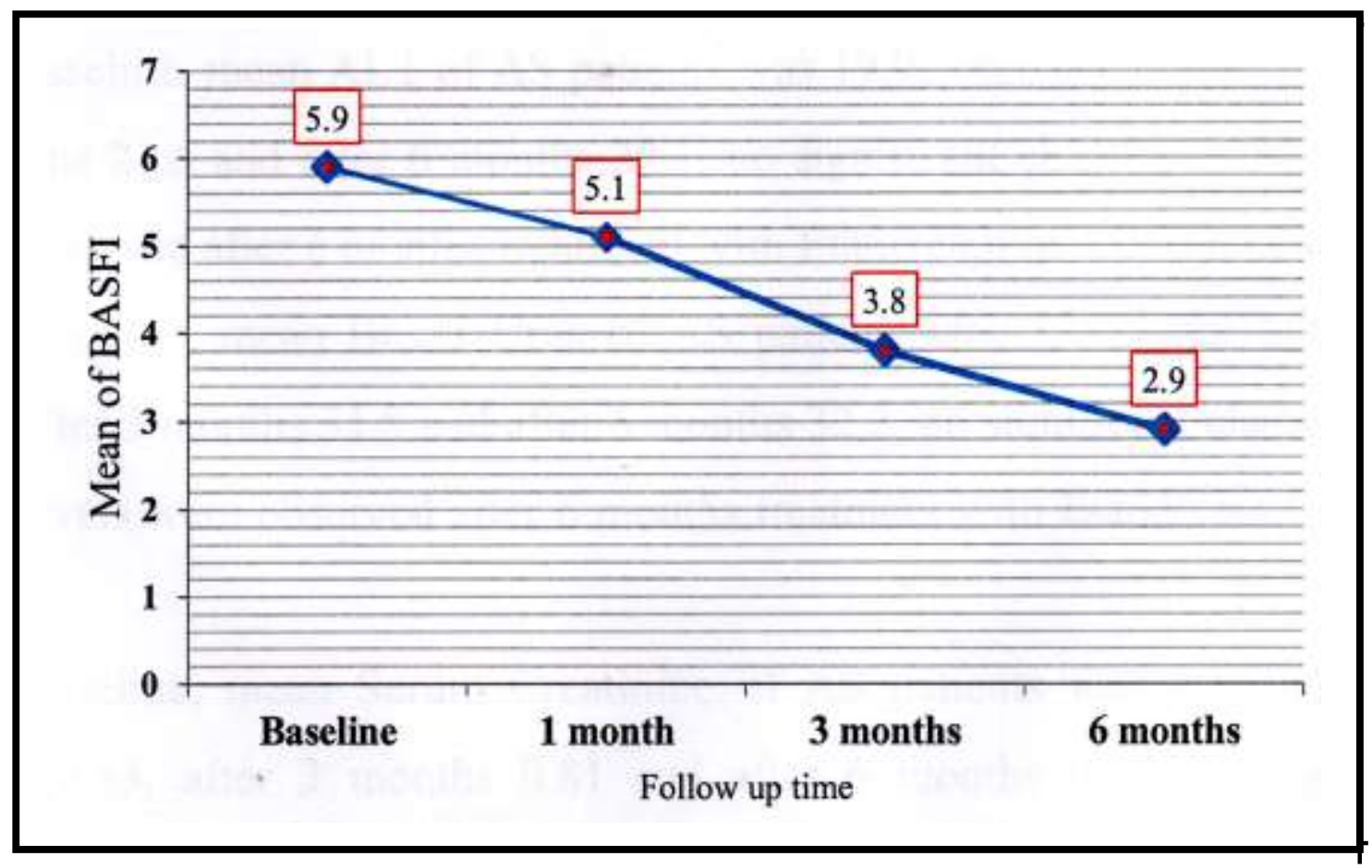

Figure 2.Changes in BASF! throughout the time of follow up with treatment. 


\section{CHAPTER THREE}

There was no significant difference in mean values of patients $\mathrm{Hb}$ after 6 Months of weekly treatment with Etancrcept $(p=0.85)$, mean value of $\mathrm{Hb}$ was 13.2at baseline, 13.3nfter I month, 13.4 after 3 months and I3.2after 6 months, table 4 .

A significant decrease in WBC count of the patients was observed after 6 month $(p<0.001)$, mean WBC count at baseline was $8.5 \times 1000$, after I month $7.5 \times 1000$, after 3 1nontl1s $6.9 \times 1000$ and after 6 months $6.6 \times 1000$, table 4 and figure 3 .

At baseline, mean ESR of AS patients was 31.2, after one month 19.86, after 3 months 18.19 and after 6 months 16.12, there was a significant decrease in ESR of the AS patients after 6 months treatment with Etanercept $(p<0.001)$, table 4 and figure 4.

At baseline, mean AST of AS patients was 22.1, after one month 22.9, after 3 months 21.7 and after 6 months 20.1, no significant changes in AST levels were observed after 6 months treatment with Etanercept $(p=0.49)$, table 4 .

At baseline, mean ALT of AS patients was 19.9, after one month 23.1, after 3 months 21.6 and after 6 months 22.1, no significant changes in ALT levels were observed after 6 months treatment with Etanercept $(p=0.31)$, table -L

At baseline, mean Blood Urea of AS patients was 33.8, after one month 33. ,2 after 3 months 31.8 and after 6 months 32.2, no significant changes in B. urea levels were observed after 6 months treatment with Etanercept $(p=0.4)$, table 4.

At baseline, mean Serum Creatinine of AS patients was 0.77, after one month 0.83, after 3 months 0.81 and after 6 months 0.87 , no significant Changes in s, Creatinine levels were observed after 6 months treatment with Etanercept $\{p=012)$ table 4 These findings indicating the safety of etanercept . . 
Table 4. Distribution of results of blood tests during different time of evaluation.

\begin{tabular}{|lccccc|}
\hline & \multicolumn{5}{c}{ Follow-up time } \\
\cline { 2 - 5 } Test* & $\begin{array}{c}\text { Baseline } \\
(\mathrm{n}=75)\end{array}$ & $\begin{array}{c}1 \text { month } \\
(\mathrm{n}=72)\end{array}$ & $\begin{array}{c}3 \text { months } \\
(\mathrm{n}=: 68)\end{array}$ & $\begin{array}{c}6 \text { months } \\
(\mathrm{n}=66)\end{array}$ & \\
\hline Hb & 13.2 & 13.3 & 13.4 & 132 & 0.85 \\
\hline WBCx 1000 & 8.5 & 7.5 & 6.9 & 6.6 & $<0.00$ I sig \\
\hline ESR & 31.2 & 19.86 & 18.19 & 16.12 & $<0.001 \mathrm{sig}$ \\
\hline AST & 22.1 & 22.9 & 21.7 & 20.1 & 0.49 \\
\hline ALT & 19.9 & 23.1 & 21.6 & 22.1 & 031 \\
\hline B.1Jrea & 33.8 & 33.2 & 31.8 & 322 & 0.40 \\
\hline S.Creatinin & 0.77 & 0.83 & 0.81 & 0.87 & 0.12 \\
\hline
\end{tabular}

- Values represented the mean. P value(Probability of error). Haemoglobin.(Hb),White Blood Cells Count(WBC)Erythrocyte Sedimentation Rate(ESR),AspartateTransaminase(AST),Alanine Transaminase(ALT).

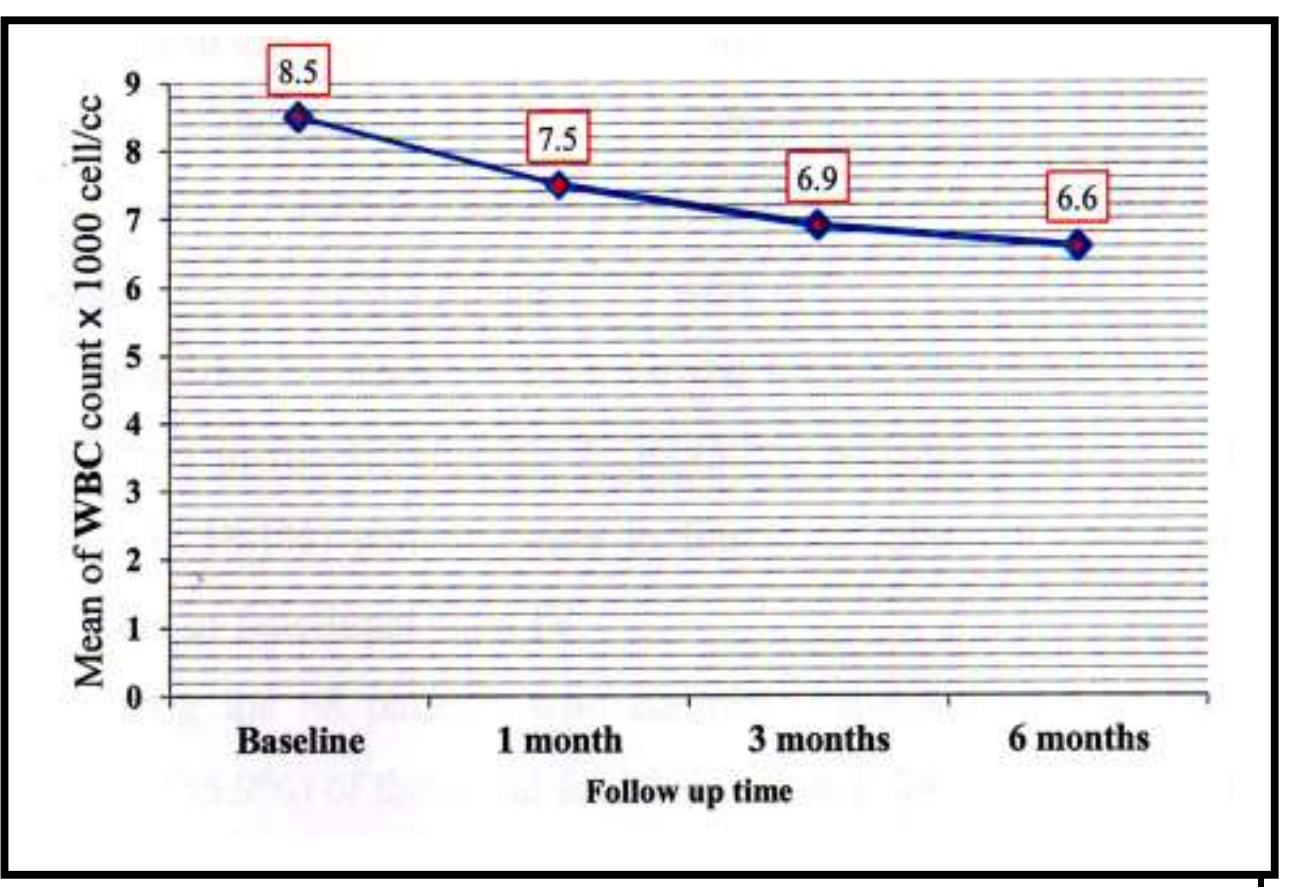

Figure 3.Changes in WBC count throughout the time of follow up. 


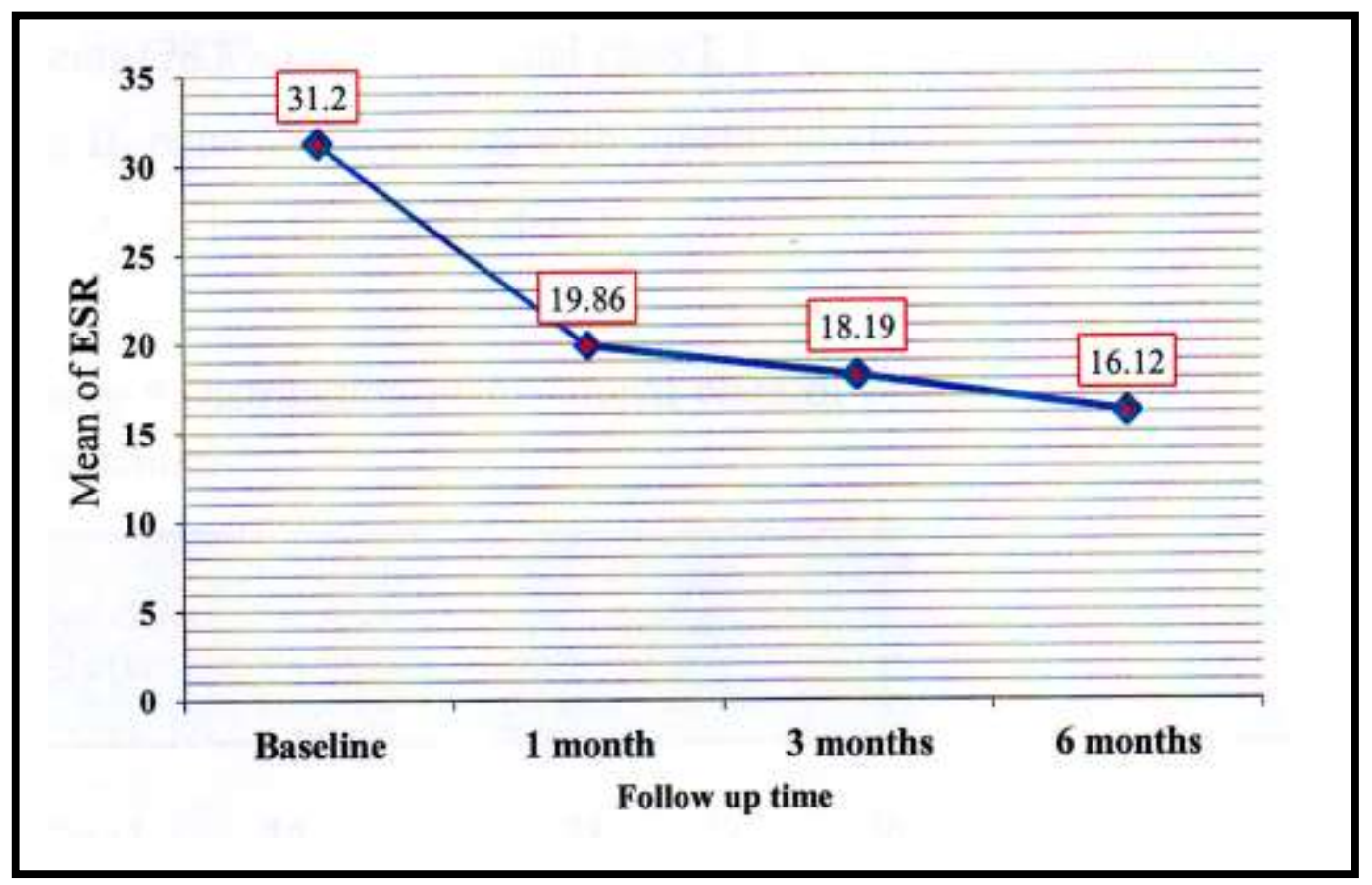

Figure 4.Changes in ESR count throughout the time f follow up.

As it shown in table 5, there was a significant changes in the functional classes of the patients; with the advancing time of follow up, there was a reduction in the frequencies of advanced classes (111 and IV) and increase in the frequencies of class I and II.

At baseline, 16 (21.3\%) AS patients were in functional class I, 35 patients $(46.7 \%)$ were in functional class II, 18 (24\%) patients were in functional class III and 6 patients (8\%) were in functional class IV.

Out of the 72 patients who followed for the first month 21 (29.2\%) patients were in functional class I, $36(50 \%)$ patients were in functional class II, $13(18.1 \%)$ patients were in functional class III and 2 patients $(2.8 \%)$ were in functional class IV.

Among the 68 patients who completed the followed up for three months, 38 (55.9\%) of them had functional class I, 24 (35.3\%) patients had functional class II, 5 (7.4\%) patients had functional class Ill andonly one patient $(1.5 \%)$ had functional class IV. 
Out of the 66 patients who completed the 6 months of follow up, 52 patients $(78.8 \%)$ had functional class I, 13 (19.7\%) patients with functional class II, none of the patient with functional class III and only one patient $(1.5 \%)$ was had functional class IV.

Table 5.Distribution of functional class of patients at different times of evaluation.

\begin{tabular}{|c|c|c|c|c|c|c|c|c|}
\hline \multirow{2}{*}{$\begin{array}{l}\text { Function\& } \\
\text { 1class }\end{array}$} & \multicolumn{2}{|c|}{$\begin{array}{c}\text { Baseline } \\
(n=75)\end{array}$} & \multicolumn{2}{|c|}{$\begin{array}{c}1 \text { month } \\
(n \cdot 72)\end{array}$} & \multicolumn{2}{|c|}{$\begin{array}{c}3 \text { months } \\
(\mathrm{n}=68)\end{array}$} & \multicolumn{2}{|c|}{$\begin{array}{c}6 \text { months } \\
(\mathrm{n}=66)\end{array}$} \\
\hline & No. & $\%$ & No. & $\%$ & No. & $\%$ & No. & $\%$ \\
\hline Class I & 16 & 21.3 & 21 & 29.2 & 38 & 55.9 & 52 & 78.8 \\
\hline Class II & 35 & 46.7 & 36 & 50.0 & 24 & 35.3 & 13 & 19.7 \\
\hline Class III & 18 & 24.0 & 13 & 18.1 & 5 & 7.4 & 0 & 0.0 \\
\hline Class IV & 6 & 8.0 & 2 & 2.8 & 1 & 1.5 & 1 & 1.5 \\
\hline Total* & 75 & 100.0 & 72 & 100.0 & 68 & 100.0 & 66 & 100.0 \\
\hline
\end{tabular}


Multiple logistic regression analysis revealed no significant association between each of age of the patients, disease duration, HLAB27, family history of Psoriasis/IBD, NSAIDs intake and duration of smoking with changes in BASDAI, BASFI and functional class, in all comparison $\mathrm{P}>0.05$, indicating that these changes were mainly due to effectiveness of Etanercept, table 7.

Table 7.Multiple logistic regression analysis of patients' characteristics and response to treatment.

\begin{tabular}{|l|c|c|c|}
\hline variable & $\begin{array}{c}\text { Standardized correlation } \\
\text { coefficients }\end{array}$ & $t$ & $\mathbf{p}$ \\
\hline Age & -0.027 & -0.092 & 0.928 \\
\hline Disease Duration & 0.219 & 0.914 & 0.377 \\
\hline HLA-B27 & 0.275 & 0.979 & 0.346 \\
\hline Family history of psoriasis IIBO & 0.457 & 1.686 & 0.116 \\
\hline NSAIDs & -0.068 & -0.253 & 0.804 \\
\hline Duration of Smoking & 0.406 & 1.253 & 0.232 \\
\hline
\end{tabular}

- P.value(value of probability of error)

- HLA (Human leukocyte Antigen)

- IBO (Inflammatory bowel disease)

- NSAIDs (No n Steroidal Anti Inflammatory drugs) 


\section{Discussion}

Ankylosing spondylitis is a chronic inflammatory disorder that occurs mainly in HI.A B27-positive individuals, and is characterized by entheseal and synovial involvement, with progressive damage and Ankylosis of the spine in the majority of patients.(7)

In the present study, 66 AS patients completed 6 month treatment with Etanerapt and follow up period. The mean age of the patients was $352 \pm 10$ years, males represented $(91.9 \%)$ of the patients. These characteristics are close to that reported by a Germany study (2004 (41) Employment is another important variable affecting the outcome in A.S. (42)

Among present patients, higher proportion of AS patients (90.7\%) were employed and only $93 \%$ of them were unemployed. This finding is in agreement with the results of study in a German study, Braun et al. (2002) reported that after a mean disease duration of 16 years, $51.5 \%$ of the patients were still employed full-time. Cessation of work occurred at a mean disease duration of 15.6 yrs. study by Although; disease progression lead to damage and loss of function which seems to be most rapid during the first 10years of disease (43)

Disease duration is difficult to conceptualize in chronic conditions where etiology and timing of pathogenic events are unknown. However, even if these were elucidated, duration would still be difficult to ascertainon an individ (44)

In the present study mean AS duration was $9.29 \pm 7$ years. This finding is in agreement with results of double-blind, placebo-controlled multicenter study on 356 patients with active AS received etanercept in USA (2006) ${ }^{(45)}$ 
This study revealed that more than one-third of the studied AS patients were current smokers, which $n$ 0nding that is in ngrcenlcnlwith $n$ study in Chinn (2013)that concluded, current smoking is associated with higher levels of disease activity, worse functional status, greater pain and overall poorer quality of life. (46)

More than half of the studied AS patients had positive HLA-827. This finding is consistent with results of USA study (1998).(47) The inflammatory Bowel Diseases (18D) were present in $2.7 \%$ of the AS patients. which is lower than that of Other studies which revealed that Between 5 and $10 \%$ of cases of AS are associated with IBD, either Crohns disease or ulcerative colitis the difference may be explained by the differences in the studies population and food type and habits. A much larger percentage of AS patients have subclinical gut inflammation manifested either by endoscopic findings or by histology . (48)

Most of studied AS patients (80\%) were NSAIDs users and this is consistent with findings of USA study (2003). (48)

History of medications used by AS patients in the present study revealed that more than half of them $(57.35 \%)$ used DMARDS, $26.7 \%$ of them used steroids, $25.3 \%$ of them used methotrexate and only $9.35 \%$ of them used biologic medications. This finding is inconsistent with results of study carried out in UK (2001), in which one-fifth of patients used biological treatment.(49)

This inconsistency might be attributed to different reasons as economic, medical knowledge and health educational differences.

This study revealed a significant improvement of BASDAI and BASFI of studied AS patients ( $p<0.001$ )during the 24-weeks follow up period. And the improvements in these response criteria continued throughout the study. Etanercept was effective in patients with persistent 
disease, despite previous treatment with NSAIDs or corticosteroids and regardless of concomitant DMARD therapy.

In the current study, etanercept improved measures of spinal mobility, which in agreement with a previous study, in UK (2001)(50)which reported resolution of entheseal abnormalities in the spine, as determined by magnetic resonance imaging, after treatment with etanercept. Suggesting that etanercept may modify the disease process as well as control the symptoms of AS.

Significant differences were observed in BASDAI and BASFI of AS patients in the present study ( $\mathrm{p}<0.001)$. A review study on electronic database of AS patients in UK (2005) (51) showed that BASDAI scores were reduced by close to 2 points at 12 weeks and Functional scores (BASFI) were reduced at 12 weeks after treatment with Etanercept.

In the present study, more than two thirds of the patients $(78.8 \%)$ were in functional class I after six months treatment, with Etanercept. This medication provides quantifiable benefits consistent with improvement of the overall disease state, not only regarding pain and disease activity but also in physical function, as assessed by BASFI. This finding is in agreement with the results of German study (2003) which had suggested that this measure is sensitive to change, even on a short-term basis.

This follow up study not only confirms the clear-cut efficacy of etanercept in the long-term treatment of active AS patients despite conventional NSAID therapy, but, in comparison with two published US trial (2003) and one European trial $\left(200 \mathrm{Ji}^{4}{ }^{4} .^{53}>\right.$, it also showed that no additional therapy with DMARDs and steroids is needed to obtain this result. This is important because many active AS patients are treated with DMARDs and glucocorticoids despite lack of proven efficacy and approval, simply because no other medical therapy had been available. (54) 
Most laboratory findings were normal except leucocytes count which shows a significant decrease after 6 months treatment with etanercept. Pancytopenia including leukopenia (someti.mes with a fatal outcome) rarely has been reported. The causal relationship to etanercept therapy remains unclear. Although no high risk group has been identified, caution is recommended if the cl.mg is to be used in patients with a previous history of significant hematologic abnormalities. All patients should be advised to seek immediate medical attention if they develop signs and symptoms suggestive of blood dyscrasias or infection (e.g., persistent fever, bruising, bleeding, pallor) while on etanercept. The drug should be discontinued if patient develops significant hematologic abnormalities.

This study revealed a significant decline in ESR (about 50\%) of AS patients after 6 months treatment with etanercept. ESR is used for assessment of treatment of AS patients with IBO/Peripheral joints, in addition to strong correlation with BASDAI of AS patients IBO/Peripheral joints.

This study revealed no significant association between each of age, disease duration, HLA-B27, family history of psoriasis/IBD, NSAIDs and duration of smoking with response to treatment. This finding is consistent with results a study in China (2012).

Although radiographic change in AS is not a well established measure of outcomethis study measured the x-ray-outcome of etanercept on sacroiliac joint and revealed no significant changes in $\mathrm{X}$ rays after 6 month treatment of AS patients with etanercept indicating that entanercept could inhibit the X-ray progression of the disease . This finding is consistent with European Medicines Agency (2010) which pointed to x-ray changes of sacroiliac joint after treatment with etanercept. 


\section{CONCLUSION}

Etanercept drug is effective and relatively safe in treatment of ankylosing spondylitis patients. 


\section{REFERENCES}

\section{References}

1. Baraliakosx, listing J, Rudwaleit M., et al. Progression of radiographic damage in patient with Ankylosing spondylitis. Defining the central role ofsyndesmophytes. Ann Rheum Dis. 2007; 66 (7): 910 -915.

2. Gran JT, Hus by G, Hordvikm, et al. prevalence of ankylosing spondylitis in males and females in a young middle aged population of Tromso, northern Norway. Ann Rheum Dis.1985; 44: 359 - 367.

3. Braun,Bollow M,Remlinger G, et al. prevalence of spondyloarthropathies in HLA-B27 positive and negative blood donors arthritis Rheum. 1998; 41 (1): 58 - 67

4. Trontzas P,Andrianakos A,Miyakis, et al. seronegative spondyloarthropathies in Greece: a population - based study of prevalence, clinical pattern, and management. The ESORDIG study. clin Rheumatol. 2005; $24(6): 583-9$.

5. DeAngelis R,Salaffi F, Grassiw.et al. prevalence of spondyloarthropathies in an Italian population sample: a regional community based study.Scand J Rheumatol. 2007; 36(1): 14 - 21.

6. Van der lindens, van der Heijde D. Antrylosing spondylitis. clinical feature. Rheum Dis. clin North Am. 1998; 24 (4): 663- 76.

7. Khan M A. update on spondyloarthropathies. Ann intern Med. 2002; $136(12): 896-907$.

8. Arthritis Research campaign - Ankylosing spondylitis case History. Arthritis Research campaign. 2009. http:/www.arc.org.uk/ arthinfo / patpubs / 6001 / 6001.asp. Retrieved2009 - 08 - 25.

9. Al-Rawi ZS, AL-shakarchi HA,Hasan F. Ankylosing spondylitis and association with histocompatibility antigen HL-AB27: an epidemic- 
REFERENCES

ological and clinical study. Rheumatology and Rehabilitation 1978; 17 : 72-5.

10. Brown MA. Break throughs in genetic studies of Ankylosing spondylitis. Rheumatology (oxford) 2008; 47 (2): 132 - 7.

1I. Reveille JD, Ball EJ, khan MA.HLA - B27and genetic predisposing factors in spondyloarthropathies. Curropin Rheumatol. 2001; 13 (4): 265 -72 .

12. Jaakola E, Herzberg!, Laihok, et al.finish HLA studies confirm the increased risk conferred by HLA-B27 homozygosity inAnkylosing spondylitis. Ann. Rheum. Dis. 2006; 65 (6): 775 - 80.

13. Reveille JD, Arnett fc.spondyloarthritis: update on pathogenesis and management. AMJ med.2005; 118 (6): 592 - 603.

14. Ebringer A. The relationship between klebsiella infection and Ankylosing spondylitis. Baillieresclin Rheumatol. 1989; 3 (2): 321-38.

15. Uzuncakaanf 0 . Evaluation of clinical activity and function impairment in smokers with Ankylosing spondylitis. Rheumatollnt 2005;25:357- 60

16. Feldtkeller E, khanM; van Der HeijdeD. et al. "Age at disease onset and diagnosis delay in HLA-B27 negative VS. Postive patients with Ankylosing spondylitis". Rheumatology intemational .2003;23 (2): 61 66, available from: (www.ncbi.nlm.nih.gov), accessed on April 15 $5^{\text {th }}$ 2013.

17. Calin A,porta $\mathbf{J}$, fries $\mathbf{J F}$, et al, clinical history as a screening test for Ankylosing spondylitis. JAMA, 1977; 237 (24): 2613-4.

18. Will R,Palmer R,Bhalla A, et al.osteoporsis in early Ankylosing spondylitis: a primary patho logical event. Lancet 1989; 2: 1483 -85. 
19. Rudwaleit M, Metter A, Listing Jet al. Inflammatory back pain in Ankylosing spondylitis a reassessment of the clinical history for application as classification and diagnostic criteria. Arthritis Rheum. 2006; 54 (2): 569- 78.

20. Maghraoui A; Extra - articular manifestations of Ankylosing spondylitis: prevalence,Eur J Internal Med. 2011; 22 (6): 554 - 60

21. Ali A,Samon CM, Seronegative spondyloarthropathies and the eye. Curropin ophthalmol. 2007; 18 (6): 476 - 80.

22. Martin TM, Smith JR, Rosenbaum JT. Anterior uveitis: current concepts of pathogenesis and interactions with the spondyloarthropathies. curropin Rheumatol. 2002; 14 (4): 337 - 41.

23. Van der Heijde D. Antkylosing spondylitis m: klippel JH, Stone JH,crofford LJ, White PH, editors. Primer on Rheumatic Disease 13 thedn. New York: Springer; 2008; 193-6.

24. Dirk Elewaut and Marco Matucci-cerinic. Treatment of Ankylosing spondylitis and extra-articular manifestations $m$ every day rheumatology practice. Rheumatology J [Internet]. 2009; 48: 1029 - 35. Available from: http://rheumatology.oxfordjoumals.org/.accessed on April $13^{\text {th }} 2013$.

25. Thomas E,Sihnan AJ,Papageorgion AC, et al. Association between measures of spinal mobility and low back pain: An analysis of new attenders on primary care,Spine 23 (2): 343 - 7.

26. Van der Linden SM,valken burg HA, Cast A. Evaluation of diagnostic criteria for ankylosing spondylitis a proposal for modification of the New York criteria. Arthritis Rheum 1984; 27: 361-68. 
27. Garrett $\mathrm{S}$, Jenkinson $\mathrm{T}$, White lock $\mathrm{K} \mathrm{H}$ et al. A new approach to defining disease status in ankylosing spondylitis: the Bath ankylosing spondylitis Disease Activity index. J Rheumatol1998; 21 (12):2286--91.

28. Calin A, Garrett S,wbitelock K H, et al.A new approach to defining functional ability in ankylosing spondylitis: the development of the bath Ankylosing spondylitis functional index. J Rheumatoll 994; 21 (12): 2281-5.

29. Dougados M,Dijkman SB, khan M, et al. Conventional treatments for ankylosing spondylitis. Ann Rheum Dis 2002; 61 (supp 13): iii 40-iii50.

30. Braun J, van den Berg R,Baraliakosx, et al; 2010 update of ASAS / EULAR recommendations for the management of ankylosing Ann Rheum Dis. 2011; 70 (6): 896-904,

31. Toivanen A,Mottonen T. " Ankylosing spondylitis: current approaches to treatment ". Bio Drugs 1998; 10 (3): 193 - 200.

32. Clain A, El Swood J.A. Prospective nationwide cross - sectional study of NSAID usage in 1331 patients with ankylosing spondylitis. J Rheumatol. 1990; 17: 801 - 803.

33. Pimentel - santos FM,Mourao AF. Spectrum of ankylosing spondylitis in Portugal Development of BASDAI, BASF! and mSASSS reference centile charts. clin Rheumatol 2012; 31: 447 - 54.

34. Zochling J, van der Heijde D, Burgos - vargas R, et al. "Assessment in As" international working group; European League Against Rheumatism. ( ASAS ) EULAR recommendations for the management of ankylosing spondylitis. Ann Rheum Dis. 2006; 65:442 - 52.

35. Keat A,Barkham N,Bhalla A et al. BSR guidelines for prescribing TNF - alpha blockers in adults with ankylosing spondylitis. Report of a 
working party of the British society for Rheumatology. Rheumatology 2005; 44: 939 - 47.

36. Gorman JD. Sack KE, Davis JCJr. Treatment of ankylosing spondylitis by inhibition of tumor necrosis factor alpha. N Eng IJ Med 2001; 1346 1356.

37. Peppel, K. A tumor necrosis factor (TNF) receptor - IgG heavy chain chimeric protein as a bivalent antagonist of TNF activity. Exp. Med. 1991;174 (6): 1483 - 9.

38. Peppel, K. Expression of a TNF inhibitor $\mathrm{m}$ transgenic mice.J. lmmunol.1993; 151 (10): 5696-703.

39. Kolls, J. prolonged and effective blockade of tumor necrosis factor activity through adenovirus - mediated gene transfer. Proc. Natl. Acad. Sci. USA.1994; 91 (1): 215-9.

40. Davis JCJr, van der Heijde D, Braun J, et al.Recombinant human tumor necrosis factor receptor (etanercept) for treating ankylosing spondylitis a randomized, controlled trial. Arthritis Rheum 2003; 48: 3230 - 3236.

41. . Brandt J, Listing J, Haibel H, Schwebig A, Braun J, et al. Long-term efficacy and safety of etanercept after readministration in patients with active ankylosing spondylitis. Rheumatology 2005; 44:342-348.

42. Moreland LW, Cohen SB, Baumgartner SW, et al. Long-term safety and efficacy of etanercept in patients with rheumatoid arthritis. J Rheumatol 2001; 28:1238-44.

43. Braun J, Pincus T. Mortality, course of disease and prognosis of patients with ankylosing spondylitis. Clin Exp Rheumatol 2002; 20 (Suppl. 28): S16-S22. 
44. Davis J C, Dougados M, Braun J, Sieper J, Heijde D, Linden S. Definition of disease duration in ankylosing spondylitis: reassessing the concept. Ann Rheum Dis 2006; 65:1518- 1520.

45. Braun J, McHugh N, Singh A, Wajdula JS, Sato R. Improvement in patient-reported outcomes for patients with ankylosing spondylitis treated with etanercept $50 \mathrm{mg}$ once-weekly and $25 \mathrm{mg}$ twice-weekly. Rheumatology 2007;46:999-1004.

46. Chen CH, Chen HA, Lu CL, Liao HT, Liu CH, Tsai CY, et al. Association of cigarette smoking with Chinese ankylosing spondylitis patients in Taiwan: a poor disease outcome in systemic inflammation, functional ability, and physical mobility. Clinical Rheumatology 2013; 32 (5): 659-663.

47. Reveille JD. HLA-B27 and the seronegative spondyloarthropathies. Am J Med Sci 1998;316(4):239-249

48. Rudwaleit M, Baeten D. Ankylosing spondylitis and bowel disease. Best Pract Res Clin Rheumatol. 2006; 20 (3):451-71.

49. Wade AG, Crawford GM, Pumford N, Koscielny V, Maycock S, McConnachie A. Baseline characteristics and patient reported outcome data of patients prescribed etanercept: web-based and telephone evaluation. BMC Medical Research Methodology 2001;11: 91-100.

50. Marzo-Ortega H, Mc Gonagle D, O'Connor P, Emery P. Efficacy of etanercept in the treatment of the entheseal pathology in resistant spondylarthropathy. Arthritis Rheum 2001;44:2112- 7.

51. McLeod C, Bagust A, Boland A, Dagenais P, Dickson R, Dundar Y, et al. Adalimumab, etanercept and infliximab for the treatment of 